\title{
Aprendizagens Expansivas Reveladas pela Pesquisa sobre a Atividade Matemática na Sala de Aula
}

\author{
Expansive Learning Revealed by Research on Classroom Mathematical \\ Activity
}

\author{
Maria Manuela David* \\ Vanessa Sena Tomaz ${ }^{* *}$
}

\begin{abstract}
Resumo
Neste artigo exploramos o potencial teórico e metodológico da teoria da Aprendizagem Expansiva com o objetivo de analisar as aprendizagens que ocorrem em sala de aula de Matemática. A análise incide sobre um conjunto de observações de práticas em sala de aula, que envolveram o uso de um procedimento escolar, a regra de três, e os seus desdobramentos quando esse procedimento foi confrontado com situações do cotidiano dos alunos. A pesquisa de campo em duas turmas do $8^{\circ}$ ano do Ensino Fundamental de uma escola pública revelou uma série de aprendizagens não previstas no planejamento inicial da professora, relacionadas à expansão de significado de um procedimento escolar (regra de três) e às formas de resolver um problema quando situações do cotidiano são introduzidas por meio de um artefato cultural (conta de água). Mostrou também como a pesquisa em Educação Matemática pode influenciar a própria aprendizagem dos sujeitos envolvidos na atividade.
\end{abstract}

Palavras-chaves: Atividade Matemática Escolar. Miniciclos. Aprendizagem Expansiva. Teoria da Atividade.

\begin{abstract}
In this article we examine the theoretical and methodological possibilities offered by Expansive Learning theory to analyze learning resulting from a problem solving classroom activity. This activity involved the use of a school procedure, rule of three, and its subsequent unfolding when students' everyday situations were confronted with a school procedure. The field research, in two 8th-grade classes from a public school, revealed a range of learning instances not anticipated by the teacher related with the meaning expansion of a school procedure (rule of three) and with the different ways of solving a problem when everyday situations are introduced by means of a cultural artifact (water bill). It also showed how research in mathematics education may influence the subjects' learning.
\end{abstract}

Key-words: School Mathematical Activity. Miniature Cycles. Expansive Learning. Activity Theory.

\section{Introdução}

\footnotetext{
* Doutorado em Educação pela Universidade de Londres, Inglaterra. Professora Titular. Universidade Federal de Minas Gerais. (UFMG), Belo Horizonte/MG. Endereço para correspondência: Av. Antônio Carlos, 6227. Pampulha, Belo Horizonte/MG, CEP: 31270-901. E-mail: manuelamsdavid@ gmail.com

Doutorado em Educação pela Universidade Federal de Minas Gerais (UFMG), Belo Horizonte/MG. Professora Adjunta. Universidade Federal de Minas Gerais (UFMG), Belo Horizonte/MG. Endereço para correspondência: Av. Antônio Carlos, 6227, Pampulha, Belo Horizonte/MG, CEP: 31.270-901. E-mail: vanessastomaz@gmail.com
} 
Neste artigo fundamentamos-nos na teoria histórico-cultural da atividade e apresentamos uma perspectiva de análise de práticas em sala de aula, estruturadas como atividade $^{l}$ escolar, que acreditamos ser ainda pouco explorada pela pesquisa em Educação Matemática. Essa perspectiva tem permitido evidenciar momentos de aprendizagem no desenrolar da atividade escolar, isto é, momentos em que práticas podem ser ditas efetivas no sentido de resultar em aprendizagens.

Nossas pesquisas estão voltadas para questões diretamente vinculadas à sala de aula com o propósito de compreender o que/como se ensina e o que/como se aprende nesse ambiente. A busca dessa compreensão nos levou a enxergar a sala de aula como espaço privilegiado onde é possível perceber quando e como ocorrem mudanças na atividade matemática escolar, e como essas mudanças podem impulsionar aprendizagens, tanto para os estudantes como para os professores.

Em trabalhos anteriores nos apoiamos em outras perspectivas socioculturais em que a aprendizagem pode ser associada à metáfora da participação, como na perspectiva da Aprendizagem Situada (DAVID; WATSON, 2008). Contudo, perante práticas que envolviam maior interface com outras disciplinas escolares ou quando situações do cotidiano dos alunos eram introduzidas nas aulas de Matemática, a perspectiva da Aprendizagem Situada mostrou algumas limitações. Por exemplo, para descrever o modo como ocorria o movimento de uma participação periférica para uma participação mais central (TOMAZ, 2007), o que para Lave e Wenger (1991) era uma manifestação de que houve aprendizagem.

Assim, buscamos outras perspectivas teóricas para aprofundar a análise da aprendizagem em sala de aula, em práticas ditas interdisciplinares, e passamos a adotar um referencial teórico assentado na perspectiva histórico-cultural da Teoria da Atividade (TA), caracterizando tais práticas como sistemas de atividades (ENGESTRÖM, 1987). Isso nos permitiu analisar as ações dos sujeitos (alunos e professores) quando participam coletivamente em sistemas de atividades e investigar a aprendizagem matemática nesses sistemas (TOMAZ; DAVID, 2008).

Em trabalhos mais recentes, revisitamos dados já analisados segundo outras perspectivas de aprendizagem (DAVID; TOMAZ, 2009; TOMAZ; DAVID, 2011; DAVID; TOMAZ, 2012; DAVID; TOMAZ, 2014) e começamos a desenvolver uma perspectiva de análise micro da estrutura da sala de aula, fundamentada na teoria da Aprendizagem Expansiva (ENGESTRÖM, 1987), fundamentada por sua vez na TA. Segundo essa

\footnotetext{
${ }^{1}$ Atividade está sendo tomada aqui em sentido amplo da Teoria da Atividade, sentido esse que vai além da ideia de tarefas, exercícios ou problemas escolares, e será melhor explicado na seção Referencial Teórico.
} 
perspectiva o que se entende por aprendizagem vai além da ideia de participação, indo na direção da ideia de expansão (ENGESTROM; SANNINO, 2010).

No presente trabalho, temos como objetivo geral: evidenciar como a perspectiva da Aprendizagem Expansiva permite aprofundar a análise de aprendizagens, que vão além da aquisição e da participação, e ocorrem em sala de aula em curtos espaços de tempo.

\section{Referenciais teóricos}

A perspectiva da aprendizagem por expansão foi desenvolvida por Engeström (1987) para descrever contextos de aprendizagem em que os aprendizes/alunos são convidados a olhar criticamente para os conteúdos e procedimentos envolvidos na atividade de que participam à luz de sua historicidade ${ }^{2}$. Assim, atividade é um conceito central nessa perspectiva da aprendizagem e suas raízes estão no conceito de atividade de Leont'ev (1979).

\subsection{Princípios da Teoria da Atividade}

Segundo Leont'ev (1979) uma atividade consiste em um grupo de pessoas (sujeitos) engajadas em um mesmo propósito, com uma direção para o seu trabalho (objeto). O que distingue uma atividade de outra é seu objeto, uma vez que ele dá a cada atividade uma direção específica. Ainda segundo Leont'ev, a estrutura de toda atividade comporta três níveis hierárquicos: no primeiro nível está a própria atividade, direcionada a um motivo; no segundo nível temos as ações, direcionadas a objetivos específicos; e no terceiro nível vêm as operações ou rotinas, que são os meios de concretização das ações, sendo este o nível de base. As ações dos sujeitos que se realizam na atividade, são provocadas/desencadeadas pelo motivo da atividade e também são direcionadas ao seu objeto, de tal forma que, para Leont'ev, o objeto de uma atividade é seu verdadeiro motivo, que pode ser material ou idealizado. Assim, ao se configurar como objeto de uma atividade humana, ele perde sua aparente neutralidade e surge como um objeto da experiência coletiva, social. As ações, por sua vez, determinam as operações a elas relacionadas, e estas são realizadas de acordo com as condições da atividade. A aprendizagem, nessa perspectiva, pode ser vista como uma mudança de nível, por exemplo, de uma rotina para uma ação mais refletida do sujeito no ambiente onde ela se desenvolve.

\footnotetext{
${ }^{2}$ Principio da historicidade diz respeito às relações dinâmicas internas e as mudanças históricas que devem ser consideradas na análise do sistema de atividades e dos seus componentes.
} 
Engeström (1987) retoma e amplia a estrutura de Leont'ev para representar um sistema de atividades coletivas. Ele acrescenta novos componentes a essa estrutura e propõe um modelo triangular para representar todos os componentes do sistema: sujeito, objeto, artefatos, divisão do trabalho, comunidade e regras.

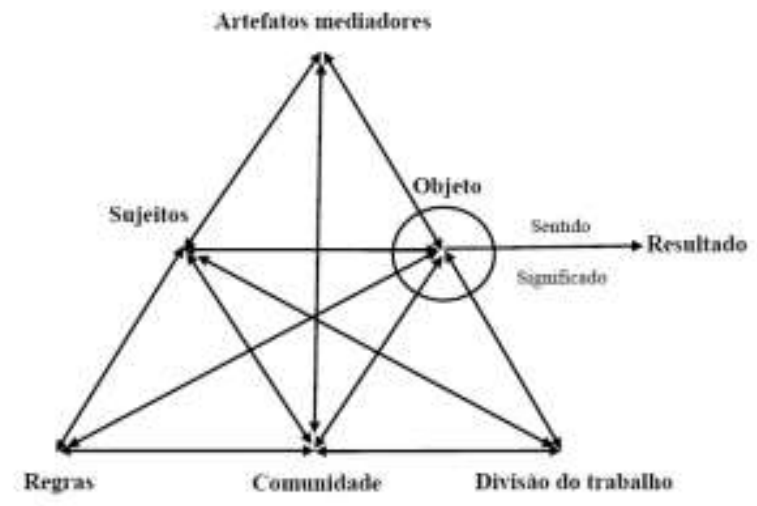

Figura 1 - Modelo triangular de Engeström (ENGESTRÖM; SANNINO, 2010, adaptado)

Nesse modelo, o sujeito pode ser um indivíduo ou grupo de pessoas engajadas em um único propósito e o poder de ação do sujeito é o foco da análise; objeto é o espaço problema na direção do qual a atividade se desenvolve; artefatos mediadores são ferramentas e signos; comunidade refere-se às pessoas que, mesmo não diretamente envolvidas nas ações dessa atividade, de alguma forma partilham o mesmo objeto; divisão do trabalho diz respeito ao status e à divisão das tarefas entre os sujeitos da atividade; e as regras se referem às normas e convenções explícitas e implícitas que regulam as ações e interações dentro do sistema de atividades. Além disso, não se pode desconsiderar que um sistema de atividades está sempre conectado a outros sistemas através de algum de seus componentes e que se um componente do sistema muda, outras mudanças devem ocorrer para ajustar o sistema como um todo. Engeström (2001) defende que as ações orientadas ao objeto são sempre, explícita ou implicitamente, caracterizadas por ambiguidade, surpresa, interpretação, atribuição de sentido e potencial para mudança.

Diferentemente de Leont'ev, para Engeström (1987) o objeto de uma atividade está diretamente relacionado com a produção de um resultado, não sendo esse objeto necessariamente o seu motivo. Uma vez que em uma atividade coletiva não se pode deixar também de considerar as necessidades e os motivos individuais, isso nos permite fazer uma distinção entre o objeto da atividade coletiva e os motivos dos sujeitos ${ }^{3}$. Engeström e Sannino (2010) acrescentam que é necessário distinguir entre o objeto generalizado, ligado ao significado compartilhado socialmente, e o objeto específico, ligado ao sentido pessoal.

\footnotetext{
${ }^{3}$ Por exemplo, numa atividade escolar pode-se distinguir entre o motivo do professor e dos estudantes.
} 
No modelo expandido de Engeström (1987) também fica ressaltado o papel central das contradições, como impulsionadoras de mudanças e de desenvolvimento da atividade humana. Segundo Engeström (2001), contradições são mais do que problemas ou conflitos, são tensões ${ }^{4}$ acumuladas historicamente dentro de e/ou entre sistemas de atividades. Associadas à percepção dessas contradições, indo na direção de resolvê-las, observam-se em geral diversas mudanças no sistema de atividades, permeando os seus componentes. Essas mudanças podem ser maiores ou menores, restritas a poucos ou a diversos componentes do sistema, e podem chegar até a uma mudança do objeto e, portanto, da própria atividade. Contradições provocam questionamentos das práticas por parte dos sujeitos, causando rupturas que podem originar transformações expansivas da atividade.

Para analisar as transformações expansivas em uma atividade, Engeström (1996) mobiliza conceitos da teoria da atividade, principalmente os de sistema de atividades e de contradições, e considera como fundamental que sejam respeitados três princípios básicos: a unidade de análise é o sistema de atividades que contextualiza e dá significado aos eventos individuais; as relações dinâmicas internas e as mudanças históricas devem ser consideradas na análise do sistema de atividades e dos seus componentes; as contradições inerentes à atividade humana devem ser analisadas como uma busca por perturbações, inovações, mudanças e desenvolvimento da atividade e de seus participantes.

Uma transformação expansiva da atividade ocorre quando o seu objeto é modificado para abarcar um horizonte de possibilidades mais vasto do que no modo anterior dela, superando contradições. Nesse processo expansivo da atividade, como resultado de um tratamento multidimensional da figura do aprendiz como indivíduo e como membro de uma comunidade, emerge uma forma de aprendizagem que se diz expansiva. É necessário ainda lembrar que as contradições são necessárias, mas não suficientes para impulsionar aprendizagem expansiva, pois, nesta perspectiva, aprendizagem é um processo de construção e solução de sucessivas contradições que se manifesta como uma mudança no objeto da atividade coletiva, que pode não ocorrer no caso de as contradições não serem resolvidas.

\subsection{Aprendizagem expansiva}

Segundo Engeström e Sannino (2010), a perspectiva da aprendizagem expansiva é qualitativamente diferente das perspectivas de aprendizagem pautadas na aquisição, com viés

\footnotetext{
${ }^{4}$ Entendemos que tensões podem ser originadas quando perspectivas diferentes entram em contato.
} 
cognitivista, e na participação, como nas abordagens socioculturais ou situadas. Nessa perspectiva os aprendizes, vistos como indivíduos e como comunidade, constroem um novo objeto para a sua atividade e o implementam na prática ao mesmo tempo em que ele está sendo criado. Daí decorre que toda a atividade tenha uma natureza sempre instável.

Para Engeström (2001), a teoria da aprendizagem expansiva tem suas origens nos estudos de Gregory Bateson (1972/2000) que distingue três níveis de aprendizagem. O nível I refere-se à aquisição e reprodução de respostas consideradas corretas para um dado contexto por exemplo, aprender a dar a resposta correta em uma sala de aula. O nível II refere-se também à aquisição, neste caso, de regras e padrões de comportamento característicos do contexto - por exemplo, como se sair bem em um teste avaliativo, como agradar ao professor. Por vezes, surgem demandas contraditórias neste nível, criando dilemas (double bind ${ }^{5}$ ) para as pessoas ou grupos. Tais dilemas podem levar as pessoas ao nível III de aprendizagem, quando passam a questionar radicalmente o sentido e significado do contexto e constroem, coletivamente, um contexto alternativo mais amplo. Bateson caracteriza esse nível como sendo o aprender sobre as/acerca das (about) aprendizagens dos níveis anteriores (BATESON, 1972/2000, p. 304).

Engeström (1987) desenvolveu a teoria da aprendizagem expansiva a partir do nível III de Bateson. Para Engeström (2001), quando uma pessoa ou grupo em uma atividade se deparam com um dilema (double bind) ou com uma contradição, isto pode levá-los a questionar o sentido e significado daquele contexto no qual a atividade se desenvolve. Desse modo, a pessoa ou grupo passará a se envolver em um contexto de crítica (ENGESTRÖM, 1991). Isso leva o grupo a construir contextos alternativos mais amplos para a atividade, criando novos padrões culturais de atividade, com ferramentas típicas e ações próprias, das quais a atividade em questão passa a fazer parte. Esse processo, que pode ser visto como um movimento do grupo, indo do nível das ações para o nível da atividade, é o que caracteriza uma atividade de aprendizagem expansiva. Ao examinar diversos estudos fundamentados na Teoria da Aprendizagem Expansiva, Engeström e Sannino (2010) encontraram em alguns deles uma ferramenta analítica denominada ciclos expansivos de ações de aprendizagem usada na interpretação de estudos de larga-escala e em processos de longa duração. A lógica de funcionamento desses ciclos expansivos é tal que um novo ciclo só começa quando um outro já alcançou um padrão de atividade relativamente estável e começou a ser questionado,

\footnotetext{
${ }^{5}$ Embora Bateson tenha utilizado esse termo para explicar principalmente os casos de esquizofrenia por ele analisados, diz-nos que, em relações normais, também podem ocorrer situações de double bind, quando um indivíduo é confrontado com mensagens contraditórias e não dá conta de comentar sobre elas (BATESON 1972/2000, p. 209). Uma tradução possível para double bind, seria dilema.
} 
ou seja, um ciclo termina quando um novo padrão da atividade torna-se conhecido e percebido como relativamente estável (ENGESTRÖM; SANNINO, 2010). Esses autores argumentam que todos os ciclos expansivos de ações de aprendizagem de larga-escala envolvem numerosos ciclos menores de ações de aprendizagem, miniciclos, que podem ser identificados em poucos dias ou em horas e que podem ser considerados como potencialmente expansivos.

Os miniciclos potencialmente expansivos de ações de aprendizagem têm se mostrado como uma poderosa ferramenta na análise micro que fazemos das atividades de sala de aula. Enquanto um ciclo expansivo de aprendizagem só é perceptível quando se toma uma perspectiva de larga escala, e é difícil de ser percebido na complexidade das dinâmicas de uma sala de aula, os miniciclos potencialmente expansivos podem ocorrer e ser percebidos até mesmo no espaço de instantes. Como esses miniciclos focam em processos de aprendizagem que ocorrem em espaços de tempo bem curtos, nos quais todos os componentes ${ }^{6}$ da atividade tomam parte, sem se priorizar as ações do professor ou dos alunos, torna-se possível perceber tensões e observar pequenas mudanças de determinados componentes da atividade em curso (DAVID; TOMAZ, 2012; DAVID; TOMAZ, 2014). Além disso, como se mostrará a seguir, podem ser identificados momentos de intensa colaboração ou resolução de problemas que resultam em aprendizagens expansivas.

Entendemos que as práticas associadas aos miniciclos potencialmente expansivos de ações de aprendizagem que vamos analisar neste trabalho podem ser consideradas como práticas efetivas na direção daquilo a que estas se propõem: ensinar e aprender Matemática. Entretanto, para manter coerência com a literatura que nos tem servido como referência, em de vez do termo práticas, utilizaremos com mais frequência os termos atividade e ações, entendendo que estes têm uma relação estreita, respectivamente, com os termos prática social (LAVE, 1993) e práticas dos sujeitos direcionadas a objetivos específicos que, por sua vez, estão inseridas em uma prática social.

Em trabalhos anteriores, nossa análise ficou centrada na discussão da interdisciplinaridade (TOMAZ, 2007; TOMAZ; DAVID, 2008) e na discussão das mudanças que ocorrem na estrutura de uma atividade matemática escolar, quando situações do cotidiano dos alunos são introduzidas na sala de aula (TOMAZ; DAVID, 2015). Aqui, centramos nossa análise nas aprendizagens expansivas que a pesquisa pode nos revelar, questão que foi apenas tangenciada pelos trabalhos anteriores. Mais especificamente, vamos: analisar as

\footnotetext{
${ }^{6}$ Objeto, sujeitos, artefatos mediadores, comunidade, divisão do trabalho e regras.
} 
aprendizagens expansivas decorrentes de uma atividade em sala de aula que envolveu o uso de um procedimento escolar, a regra de três, quando esse procedimento foi confrontado com situações do cotidiano dos alunos.

\section{0 estudo das relações proporcionais na escola: o uso da regra de três}

O material empírico a que vamos nos remeter foi coletado por uma das autoras deste artigo para sua pesquisa de doutorado (TOMAZ, 2007), fundamentada na perspectiva da etnografia como lógica de investigação na educação (GREEN; DIXON; ZAHARLICK, 2003). Nela se fez observação participante na sala de aula pelo período de um ano letivo, lançando mão de notas de campo, registro em áudio e vídeo e entrevistas com alunos e professores. A pesquisa foi realizada em uma escola pública da região metropolitana de Belo Horizonte, Minas Gerais, em duas turmas de alunos de $8^{\circ}$ ano do Ensino Fundamental. Os sujeitos da pesquisa foram os 70 alunos dessas turmas, com idades entre 12 e 13 anos, que não apresentavam discrepâncias de nível socioeconômico e desempenho escolar, e sua professora de Matemática, Telma ${ }^{7}$. Telma era experiente, pois no momento da pesquisa possuía 23 anos de atuação na Educação Básica, tinha um bom relacionamento com os alunos e, segundo estes e outros membros da comunidade, era uma boa professora de Matemática. Realmente, durante o período que acompanhamos suas aulas observamos que ela criava muitas oportunidades para que os alunos participassem ativamente das atividades em sala de aula. Durante a maior parte do tempo de observação, as aulas de Telma tinham uma estrutura parecida: introduzia um novo conteúdo com problemas tipicamente escolares ${ }^{8}$; discutia as diferentes estratégias utilizadas pelos alunos; na sequência, apresentava um procedimento escolar, canônico, a título de sistematização e concluía com mais atividades de resolução de problemas ou de manipulação do procedimento ensinado. Esta mesma estrutura de aula foi utilizada quando da introdução da regra de três para resolução de problemas que envolviam raciocínio proporcional, aulas que fazem parte da sequência a que nos referimos.

Após a introdução da regra de três, fugindo um pouco da rotina das aulas, a professora propôs aos alunos uma atividade de resolução de problemas para cálculo de consumo de água, utilizando dados fornecidos nas contas de água de suas casas para responder as perguntas do problema: Qual o número de dias de consumo?; Qual a média de consumo da família por

\footnotetext{
${ }^{7}$ Os nomes dos alunos e da professora são fictícios.

${ }^{8}$ Problemas tipicamente escolares são aqueles com uma estrutura tal que existe um procedimento escolar que se ajusta perfeitamente a ela.
} 
dia?; Qual a média de consumo por pessoa?; Qual a média de consumo por pessoa, por dia?; O que você irá fazer para economizar água em sua casa?. Para explicar como os alunos deveriam resolver o problema, a professora calculou a média de consumo da sua família, por dia, utilizando dados de sua própria conta e orientou os alunos que fizessem o mesmo com os dados das suas respectivas contas. Essa proposta fazia parte de um trabalho mais amplo, englobando outras disciplinas escolares e instituições sociais e religiosas, para abordar com os alunos o problema da escassez de água potável e a necessidade de um consumo consciente. Com esses problemas Telma tinha por objetivo mostrar para os alunos que a regra de três se aplicava em situações do cotidiano deles. Ainda dentro da discussão do tema Água e após a atividade com a conta de água, Telma propôs outro problema envolvendo uma tabela publicada em uma revista de grande circulação nacional que permitia comparar o consumo de água em situações rotineiras (escovar dentes, lavar carro, utensílios domésticos, etc), estando a torneira aberta ou fechada. A expectativa da professora era, novamente, que os alunos percebessem aplicações da regra de três no cotidiano e fizessem uso dela para realizar os cálculos.

\subsection{A regra de três}

Temos percebido em nossos contatos em escolas do Ensino Fundamental que, tal como Telma, na prática de sala de aula muitos professores continuam dando bastante importância ao ensino da regra de três e utilizando o termo regra de três para significar um conjunto de procedimentos, que é diferente do procedimento aritmético originalmente associado ao termo. Entretanto, apesar das orientações dos PCNs (BRASIL, 1998) darem abertura para que os professores continuem ensinando a regra de três, não lhe é dado grande destaque. Ela é simplesmente recomendada como possível estratégia para resolução de problemas que envolvem grandezas direta ou inversamente proporcionais no terceiro e quarto ciclos.

Em sala de aula, Telma apresenta a regra de três como um conjunto de procedimentos numéricos e algébricos, associados a um esquema visual, destinado a facilitar a resolução de problemas que envolvem grandezas proporcionais (diretamente ou inversamente); alguns valores dessas grandezas são conhecidos e pretende-se achar um valor desconhecido, mantendo as relações de proporcionalidade; o esquema visual ajuda a organizar os dados de tal forma a facilitar a aplicação dos procedimentos para achar esse valor desconhecido. A construção desse esquema visual se apoia em uma avaliação numérica da variação das 
grandezas (supostamente proporcionais) para determinar se elas são direta ou inversamente proporcionais, registrando com sinais $(+\mathrm{e}-$ ) o resultado dessa avaliação. Em segundo lugar, este esquema é usado para definir a posição dos números na equação algébrica que determina o valor desconhecido. Em última instância, a definição dessas posições é equivalente ao uso do procedimento algébrico padrão, multiplicar cruzado e resolver para $x$. Finalmente a equação é resolvida. A estratégia usada por Telma é na verdade um atalho para se obter a equação algébrica de forma simplificada. Segundo Telma, tal como para muitos professores brasileiros, fazer esse conjunto de procedimentos é resolver uma regra de três, pois tomam-se os três valores dados para encontrar o valor desconhecido.

\subsection{Atividade matemática escolar como sistema de atividades}

Na presente análise das aulas da professora Telma, vamos retomar e aprofundar a discussão empreendida em Tomaz e David (2015). Nesse trabalho focamos inicialmente nas aulas de resolução dos problemas da conta de água e, posteriormente, utilizando o princípio da historicidade da atividade (ENGESTRÖM, 1987), selecionamos as aulas que as antecederam, momento em que a regra de três foi introduzida e, a que as sucedeu, resolução de problemas de redução de consumo de água em situações rotineiras, sendo que em todas se propunha a resolução de problemas que envolviam raciocínio proporcional. Desse modo, usando o referencial da Teoria da Atividade, foi possível estruturar essas aulas como uma constelação de três sistemas de atividades interconectados: Regra de Três $\left(\mathrm{A}_{0}\right)$, Problemas de Consumo de Água das Famílias $\left(\mathrm{A}_{1}\right)$, composto por dois subsistemas, e Problema de Redução de Consumo de Água $\left(\mathrm{A}_{2}\right)$ (Figura 2). Com o detalhamento de seus componentes, obtidos por meio de sucessivos movimentos de ajustes do foco das lentes de análise, foi possível apreender as especificidades da atividade matemática escolar, quando nela são introduzidas situações do cotidiano dos alunos. 


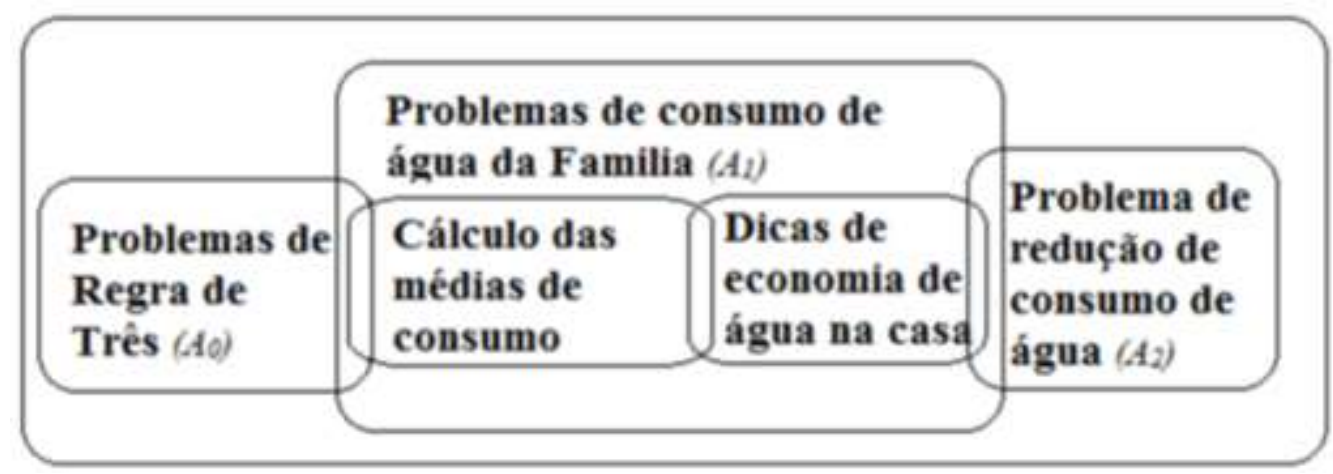

Figura 2- Constelação de sistemas de atividades relacionadas a problemas que envolviam raciocínio proporcional (Fonte: As autoras, 2015).

Uma vez identificados os componentes de cada atividade que compõe a constelação de sistemas, torna-se possível perceber tensões entre esses componentes quando, por exemplo, perspectivas diferentes do professor e dos alunos sobre o objeto da atividade entram em contato. Por sua vez, quando o pesquisador analisa o sistema de atividades do ponto de vista da sua historicidade, torna-se possível perceber como determinada(s) tensão(ões) vai(ão) se acumulando, gerando uma contradição no sistema de atividades.

As tensões percebidas em Tomaz e David (2015) geraram flutuações/transformações do objeto da atividade que, ao se avolumarem, culminaram em uma contradição entre a regra de três, vista como um procedimento escolar genérico, e os procedimentos específicos aplicáveis a situações do cotidiano dos alunos. Entretanto, observamos mudanças na estrutura da atividade escolar que geraram um novo padrão para ela e a superação da contradição, uma vez que a regra de três, objeto inicial da atividade, gradualmente, passou a ser apenas um artefato nas outras atividades. A superação dessa contradição pode ser caracterizada como uma transformação expansiva da atividade (ENGESTRÖM, 1987). Essa transformação gerou, por sua vez, aprendizagens expansivas por parte dos sujeitos, quando analisadas dentro da constelação de sistemas $\mathrm{A}_{0}, \mathrm{~A}_{1}$ e $\mathrm{A}_{2}$. Os alunos começaram a questionar a regra de três como um procedimento apenas mecânico e aplicável na resolução de qualquer tipo de problema envolvendo raciocínio proporcional e a professora começou a perceber a complexidade de se introduzir situações do cotidiano em sala de aula, ainda que somente para mostrar as aplicações de um procedimento algébrico.

Porém, a partir dos resultados apresentados em Tomaz e David (2015), aqui sintetizados, surgiu um novo interesse de investigar a ocorrência de outras aprendizagens relacionadas com a expansão do significado do procedimento regra de três, que não foram alvo desse trabalho. Com esse objetivo, vamos empreender uma nova análise do subsistema "Cálculo das médias de consumo" do sistema $A_{1}$ (Figura 2), focado na resolução dos 
problemas da conta de água. Nessa nova análise, vamos tomar como ponto de partida as tensões associadas ao uso da regra de três nesse subsistema, já identificadas em Tomaz e David (2015): T1 - Discrepância entre os modos de ver os cálculos realizados pela professora: para a professora, vistos como objeto generalizado e para os alunos, vistos como objeto específico; T2 - Discrepância entre as médias calculadas pelos alunos e a média expressa na conta da Copasa ${ }^{9}$; T3 - Dilema quanto à escolha da regra para determinar o número de pessoas para o cálculo das médias: contar apenas os membros da família ou contar todos (familiares ou não, humanos ou não) que consomem água na casa; T4 - Dilema quanto à sequência de cálculos que o aluno deverá adotar: usar o resultado da média por pessoa ou da média diária calculada anteriormente, ou usar a média diária informada na conta de água; T5 - Dilema para definir quais grandezas estão associadas à palavra consumo: valor monetário; volume; tempo; número de pessoas.

\section{Miniciclos potencialmente expansivos de ações de aprendizagem}

Para analisar as outras aprendizagens decorrentes das tensões acima, adotamos a mesma perspectiva histórico-cultural da Atividade (ENGESTROM, 1987) que, segundo Russell (2009), produz um nível de análise intermediário que vai além da microanálise do fenômeno, mas não se propõe a fazer generalizações no nível macro, comuns em estudos que fazem análises culturais e sociológicas. Assim, vamos, em primeiro lugar, descrever quatro miniciclos potencialmente expansivos, que foram identificados, e em seguida apresentar as aprendizagens expansivas percebidas em cada um deles.

\subsection{Caracterização dos miniciclos}

A partir da identificação de um ciclo expansivo de ações de aprendizagem sobre o uso da regra de três em problemas que envolvem raciocínio proporcional, relacionado à superação da contradição entre a regra de três, vista como um procedimento escolar genérico e os procedimentos específicos aplicáveis a situações do cotidiano dos alunos, ajustamos nossas lentes de análise para identificar miniciclos potencialmente expansivos de ações de aprendizagem que ocorrem em períodos de tempo mais curtos (ENGESTRÖM; SANNINO,

\footnotetext{
${ }^{9}$ Companhia de Saneamento Básico de Minas Gerais.
} 
2010). Desse modo, conseguimos caracterizar pelo menos quatro miniciclos potencialmente expansivos de ações de aprendizagem, associados às tensões T1, T2, T3, T4.

O primeiro miniciclo se inicia quando os cálculos a serem feitos pelos alunos deixam de se ajustar às orientações de uso de regra de três dadas pela professora, dando origem à tensão T1, como mostram os excertos de entrevistas com alunos e professora.

Vanessa: Você teve dificuldade para fazer este trabalho?

Cássia: Tive porque eu não estava entendendo ... como que era ... porque a professora explicava sobre cada pessoa... assim ... que morava em casa...e eu que morava em condomínio não sabia como que era...

Romero: Ah. mais ou menos porque minha conta era diferente de todas as outras... (Entrevista com alunos, 16/03/2004)

Vanessa: Qual foi sua maior dificuldade ao conduzir esse trabalho? Em que momento você teve maior dificuldade de liderar esse trabalho?

Telma: Tiveram dois erros... então na sala 05... Os alunos ficaram muito agitados...alguns meninos com a conta, outros sem...isso foi uma coisa complicada...nós tínhamos alunos que não tinham nem conta de água...pegou conta de luz.......] quando os dados são muito diferentes...fica muito complicado...eu senti dificuldade de início com os dados muito diferentes primeiro...depois não, foi rendendo...outra coisa com relação a própria disciplina da turma...e na sala 05 na hora que nós terminamos que era para fechar e fazer aquela discussão legal...aí bate o sinal...acabou a aula...então o fator tempo é uma coisa complicada nesse tipo de atividade... (Entrevista com a Telma, 30/03/2004)

Os alunos começam a questionar as orientações dadas que seguiam o padrão da atividade anterior $\left(\mathrm{A}_{0}\right)$, em que a regra de três era o procedimento que se ajustava perfeitamente aos cálculos a serem efetuados. Na sequência, a professora passa a atender os alunos e responder perguntas particulares relacionadas aos dados de suas contas. Entendemos que nesse momento os alunos percebem que os cálculos feitos pela professora não podem ser simplesmente replicados com os seus dados, pois terão de buscá-los em suas próprias contas. Eles começam a desenvolver suas estratégias e procedimentos de cálculo, que são legitimados pela professora, atenuando a $\mathrm{T} 1$, e cria-se, momentaneamente, um novo padrão para a atividade em curso.

Seguindo as orientações gerais da professora, após a realização do primeiro cálculo, do consumo médio diário da família, os alunos deveriam fazer a comparação entre o resultado encontrado por eles e a média expressa pela Copasa na conta de água. Quando os alunos percebem discrepâncias entre essas duas médias ou quando não era possível fazer a comparação porque a conta de água de alguns deles não exibia a média diária (caso do Romero), inicia-se um segundo miniciclo, desencadeado pela tensão T2.

1. Telma: na minha conta... olha só... os metros cúbicos diários dão...0,84...ou seja... dão 840 litros...por quê?? Por que está arredon...dado...o computador da Copasa arredondou... 
(...) (a professora passa mais ou menos um minuto e meio atendendo os alunos e respondendo perguntas particulares relacionadas aos dados desses alunos e o arredondamento feito ou a serfeito))

2. Telma: olha só gente...vamos anotar... nossa primeira observação...no meu caso...observação....olha só...observação:... a Copasa arredondou meu consumo médio diário para 840 litros...por quê? porque lá ((conta da professora)) está assim oh:....0,840 metros cúbicos...mas o metro cúbico não é igual a mil litros?... é igual a 0,840 vezes mil litros isto equivale...igual a 840?...litros...nas minhas contas dá isso (839) e na da Copasa foi arredondado para $840 . .$. olha só 839 é muito próximo de $840 .$.

3. Alunos: ...só que o meu não ...

4. Joaquim: o meu também não...

5. Telma: não tem problema...

((seguem-se vários comentários simultâneos dos alunos sobre o arredondamento dos seus dados na conta, quando comparado com os cálculos que eles fizeram)

6. Telma: Não tem problema...

(...)

8. Joaquim: e no caso que foi $800 . .$. o que eu ponho?

(...) ((os alunos falam ao mesmo tempo. Cada um querendo uma explicação sobre a situação apresentada em sua própria conta))

(...) ((os alunos começam a mostrar à professora que algumas contas da Copasa não têm o consumo diário expresso, como em outras))

10. Romero: viu professora...

11. Telma: se em alguma hipótese não tem o consumo diário...((fala para a turma))

12. Telma: coloca a observação não ...não... a observação é só nas contas que (chega assim) esse consumo diário médio...((responde para um aluno em particular))

((novamente a professora é interrompida para discutir as particularidades da conta de um aluno, enquanto outros estão fazendo perguntas para ela e para os colegas e até para mim)) ((duração deste trecho 2,5 minutos $)$ )

13. Telma: ((retornando para a turma)) gente...vamos fazer...o consumo médio diário por pessoa...então nós vamos colocar os litros e o número de...

14. Alunos: pessoas...

15. Cássia: então quer dizer que a Copasa arredondando... eles estão ganhando um tanto de água a mais...

16. Telma: não porque a gente paga pelos metros cúbicos...eles pegam pela média diária... tá? ...gente...litros...eu gasto 26000 de água... mensal...quantas pessoas são na minha casa? (Gravação, 08/03/2004)

Os questionamentos dos alunos levam a professora a direcionar suas orientações para casos particulares e, a partir daí, entendemos que se estabelece, momentaneamente, um novo padrão da atividade, quando a professora parece abrir mão da comparação das médias e aceitar os cálculos dos alunos, ainda que simultaneamente ela continue usando a média da Copasa nas suas orientações gerais, encerrando-se o segundo miniciclo.

Dando sequência aos cálculos, a professora novamente utiliza dados da sua conta, contabilizando o número de pessoas de sua família para o cálculo da média de consumo por pessoa (Linhas $16 ; 18$ ) e orienta os alunos para que façam o mesmo. Entretanto, uma aluna faz um questionamento que desencadeia a tensão T3, sobre os critérios para definir o "número de pessoas", dando início a um terceiro miniciclo potencialmente expansivo de ações de aprendizagem. 
17. Sônia: oh:.... professora?

18. Telma: seis ...

19. Sônia: professora aqui... na minha casa ...eh:: meu irmão...quase não mora lá porque ele só vem final de semana...

20. Telma: mas...tem alguém que trabalha lá na sua casa?

21. Sônia: tem sim...Cleusa trabalha dia de segunda-feira..

22. Telma: trabalha quando?

23. Sônia: dia de segunda...

24. Cássia: oh... professora...lá em casa...

((alunos começam a contar e questionar, falando ao mesmo tempo, o número de pessoas que vivem e trabalham nas suas casas até número de animais depois do questionamento da Sônia))

25. Cássia: olha para você ver...tem uma moça ...((devido ao ruído não foi possível transcrever a resposta da professora))

26. Telma: muito bem...

27. Cássia: e tem uma outra lá que ...vai arrumar o condomínio... não é todo dia... então eu contei como uma pessoa

(...)

29. Telma: então olha só...26000 litros são gastos por seis pessoas...se eu quero o gasto por pessoa...são quantas pessoas?

30. alunos: uma...

31. Telma: uma pessoa vai ter...

32. Alunos: x... (Gravação, 08/03/2004)

Em entrevista, Sônia esclarece a sua dúvida e o modo como ela chegou ao número de pessoas para o cálculo da sua média, fracionando os consumidores da casa:

9. Vanessa: E aí... a partir daí você fez a conta... na hora ... por que você ficou com essa dúvida... por que você pensou nisso?

10. Sônia: ué...está lá...é para pegar a média de cada pessoa...mas eu não sabia se precisava contar com meu irmão porque ele não ficava lá... se precisava contar com a faxineira... porque a faxineira num... ela ...não toma banho...essas coisas assim... não é xingando ela não...mas é porque ela tem vergonha assim...mas ela gastava água para lavar louça...lavar passeio...ela até tomava banho lá ...mas tomava duas vezes na semana para ir para festa...essas coisas...aí eu contei metade para ela e metade para o outro...

(...)

17. Vanessa: então quer dizer que esse número cinco aqui que você decidiu por ele aqui...ele é diferente dos cinco operários daqueles problemas antigos lá?

18. Sônia: ele é porque foi meio que...ia ser para 4,5...ou 4,6...mas foi 5...por causa de Cleusa e por causa de Pedro...

19. Vanessa: então essas 5 pessoas...não são... necessariamente...pessoas diferentes...

20. Sônia: é... (Entrevista, 28/05/2004)

Tal como no miniciclo anterior, um novo padrão para a atividade se estabelece a partir dos questionamentos dos alunos, quando a professora passa a aceitar e reforçar os critérios utilizados por eles para a definição do número de pessoas, embora nas orientações gerais continue se apoiando no número de pessoas da sua família, que era a interpretação dada inicialmente por ela.

O quarto miniciclo se inicia quando a professora tenta orientar os alunos a fazer o cálculo do consumo médio diário por pessoa utilizando a regra de três e montando o esquema 
visual que ela introduziu nos problemas anteriores. Neste caso, os cálculos se tornam mais complexos porque o número de grandezas envolvidas é maior que nos casos anteriores e os alunos teriam de definir quais grandezas devem ser consideradas para calcular a média. Além disso, havia diferentes opções quanto à forma de organizar esses cálculos: utilizar uma regra de três composta, ou uma regra de três simples, tomando por base um cálculo anterior, ou ainda fazendo simplesmente divisões. De imediato surgem as tensões T4 e T5, relacionadas, respectivamente, à sequência de cálculos que o aluno deverá adotar para responder a pergunta e às grandezas que estão associadas à palavra consumo, como mostra o excerto abaixo:

81.Telma: consumo médio diário de água por pessoa... então se eu estou falando em consumo eu estou falando em?....

((falam ao mesmo tempo e não foi possível compreender $)$ )

82.Telma: em ...que unidade?

83.Armando: dinheiro

84.Telma: não...

85.Dayse: dia...dia...

86.Neusa: por dia...

87.Telma: não...consumo...consumo é dia?

88.Sônia: não...consumo é litros

89.Telma: litros...

90. Sônia: o outro é dia

91.Armando: oh! professora...não é tudo pessoa não?...

((vários alunos falam ao mesmo tempo entre eles e com a professora))

92.Telma: (...) qual outra grandeza...

93.Neusa: por dia

94.Telma: não

95.Neusa: DIA...

96.Armando: pessoas

97.Sônia: mas como é que vai por em dias? ...

((segue discussão...vários alunos falam ao mesmo tempo))

98. Neusa: Professora?...Professora? você pega o 4000 que está dividido por pessoa e já está a quantidade por dia.... professora...eu estou fazendo por dia...

99. Telma: eu vou pegar....ela ((Neusa)) falou que podia pegar o consumo mensal...e dividir pela quantidade de dias...que o meu era 31...aí está (cada um com o seu) eu vou optar por fazer pelo este consumo médio da Copasa...

((alunos perguntam alguma coisa sobre a observação feita pela professora e ela confirma))

100. Telma: é...então a Copasa não falou que eu tenho um consumo médio diário de 840 litros ?

101. Neusa: minha folha não vai caber não...

102. Telma: ...(indicado) 840 litros ... para seis pessoas...se eu quero o consumo de uma pessoa...vai ser? (Gravação, 08/03/2004)

A formulação da pergunta "Qual a média de consumo por pessoa, por dia?" requeria outro padrão da atividade no que diz respeito ao uso da regra de três em relação ao padrão anterior, pois envolve um número maior de grandezas e permitia um leque maior de opções para a sequência de cálculos. Além disso, após a interferência da professora (Linha 81), a palavra consumo, antes associada a volume de forma tácita, torna-se ambígua podendo ser 
associada, pelo menos, duas grandezas diferentes: dinheiro e volume de água. Ampliam-se neste miniciclo as possibilidades de escolhas e de tomada de decisões a serem feitas pelos alunos (Linha 99) quanto aos procedimentos de resolução de problemas que trazem situações do cotidiano dos alunos. Um novo padrão da atividade se estabelece quanto ao uso do procedimento regra de três, que passa a ser considerado como uma das possibilidades de cálculo, como mostra o aluno Rodrigo em entrevista:

19.Vanessa: mas você na hora que você foi fazer as contas aqui ((mostrando o trabalho do aluno))... o que você usou de matemática para fazer isto...

20.Rodrigo: eu... foram duas contas que eu usei de matemática... porque esta já tinha lá... esta também não...então foi esta conta e esta conta que eu usei... ela ensinou de um jeito mas eu fiz de outro jeito que eu já sabia... eu fiz na primeira... tinha um número... eu dividi este número pela quantidade de pessoas que tinha na minha família e achei... diferente do que ela faz... (...)

43.Vanessa: ah... tá... nos probleminhas que a Telma deu lá ... você fazia com regra de três ou deste seu jeito?

44.Rodrigo: uhm... depende... no começo eu fazia regra de três ... depois quando entrou em porcentagem aí... eh:: aí ... os mais fáceis... igual eu te falei...os mais de fazer a divisão... zero... cinco...dois... assim... eu fazia ... do meu jeito... e os outros mais difíceis eu fazia com regra de três... (Entrevista, 25/03/2004)

\subsection{Outras aprendizagens expansivas relacionadas com o uso da regra de três em situações do cotidiano}

Quando consideramos os quatro miniciclos potencialmente expansivos de ações de aprendizagem descritos na seção anterior, percebemos aprendizagens expansivas que ocorrem em curtos espaços de tempo, relacionadas às formas de resolver um problema quando situações do cotidiano dos alunos são introduzidas por meio de um artefato cultural (conta de água). Já no primeiro contato com a conta de água, que compõe o primeiro miniciclo, os alunos precisaram compreender que se tratava de um tipo de problema em que os dados não estão expressos no enunciado, como nos problemas anteriores. Portanto, precisavam ser extraídos do formulário que, por sua vez, não foi estruturado propositalmente de forma a resolver problemas escolares. Essa compreensão só ocorreu quando, no curso da atividade, os alunos foram percebendo que os exemplos de cálculos dados pela professora não podiam ser simplesmente replicados pelos seus próprios cálculos, dados que serviam apenas como referência. Instala-se, assim, nesse miniciclo um ambiente que lhes possibilitou aprender que, mesmo que seja proposto um procedimento de cálculo comum a todos, existem diferentes maneiras de usar os dados particulares retirados do formulário. No decorrer do segundo miniciclo os alunos calculam a primeira média, após entenderem como resolver o problema e novas aprendizagens podem ser novamente percebidas, algumas relacionadas a conteúdos de 
Matemática e outras às formas de resolver um problema, cujos dados são originados de atividades do seu cotidiano. Criaram-se oportunidades para que eles aprendessem sobre as regras para arredondamento de números decimais e para a transformação de unidades de medida ( $\mathrm{m}^{3}$ para litros). Além disso, a constatação de que a medida expressa pela Copasa pode não coincidir com a média calculada pelos alunos, os levou a atentar para o fato de que o arredondamento de um número, quando este reflete situações do seu cotidiano, pode ter desdobramentos na sua vida. No caso específico em análise pode influenciar no valor a ser pago pelo consumo de água: "então quer dizer que a Copasa arredondando... eles estão ganhando um tanto de água a mais..." (aluna Cássia). Essas aprendizagens desencadeiam a tomada de consciência por parte dos alunos sobre resolução de um problema que traz uma situação da sua vida, ainda que faça uso de estratégias e procedimentos escolares.

Como um dos objetivos da professora era conscientizar os alunos sobre o consumo excessivo de água, as perguntas por ela propostas buscavam um refinamento dos cálculos do consumo da família, começando pelo consumo médio mensal e depois o cálculo da média de consumo por pessoa, que caracterizou o terceiro miniciclo. Entretanto, esse cálculo só se tornou possível quando os alunos perceberam que naquele tipo de problema nem todos os dados estavam expressos no formulário da conta e que eles mesmos teriam de criá-los, uma vez que teriam de refletir suas situações particulares. O próprio número de pessoas definido pelos alunos adquire diferentes significados, pois uns resultam de uma contagem um a um dos membros da família e outros, como no número definido por Sônia, resulta de uma estimativa do somatório dos consumos das pessoas que frequentam a casa. Para isso, a aluna levou em consideração o tipo de atividade e o tempo que essas pessoas permanecem em casa. Nesse sentido, amplia-se o significado para os números, quando utilizados para resolver problemas que envolvem situações do cotidiano dos alunos. Finalmente, no decorrer do quarto miniciclo percebe-se que o novo padrão da atividade exigido reflete uma aprendizagem relacionada ao fato dos alunos tomarem a iniciativa de propor uma sequência de cálculos que muda o rumo que estava sendo adotado pela professora. Eles demonstram um grau de autonomia que lhes permite optar entre diferentes formas de fazer o cálculo proposto (a média de consumo diário por pessoa) e argumentar com a professora sobre a eficácia de sua escolha.

Essa análise das aprendizagens percebidas nos miniciclos, quando tomada em uma perspectiva mais abrangente dos ciclos expansivos de ações de aprendizagem, aprofunda e amplia a análise empreendida em Tomaz e David (2015) porque evidencia a complexidade do processo que levou à superação da contradição instalada no sistema de atividades e resultou numa expansão de significado da regra de três. Esta antes era vista como um procedimento 
escolar ajustável a problemas de proporcionalidade e, após a resolução dos problemas que envolvem raciocínio proporcional, passa a ser vista como um dos possíveis procedimentos para resolver esse tipo de problema, como registra Rodrigo em sua entrevista (Linha 44).

Por outro lado, essa análise também mostrou como nem todas tensões geram necessariamente ações de aprendizagem, como pode ter ocorrido com a tensão T5. Apesar de o padrão da atividade ter sido questionado em função do dilema gerado pela necessidade de definir quais as grandezas intervenientes, no intervalo de tempo que tomamos para análise, não chega a se estabelecer um novo padrão para a atividade. Neste caso, o que poderia se configurar como um miniciclo em torno desse dilema parece ter se tornado apenas um evento isolado. Como afirmam Engeström e Sannino (2010, p.11), “uma investigação cuidadosa pode revelar um emaranhado de ações de aprendizagem dentro de esforços em curtos espaços de tempo." Acrescentam, entretanto, que pode ocorrer que muitas transformações em sistemas de atividade não sejam predominantemente expansivas e que, em consequência disso, um ciclo mais amplo pode tornar-se estagnado, regressivo, ou ainda se desintegrar.

Com relação às aprendizagens da professora, percebemos que ela toma consciência da complexidade desse tipo de atividade em sala e pontua mais algumas dificuldades.

50.Telma: é porque inclusive Vanessa ...além dos dados da conta ... aqui olha...além dos dados da família...dos metros...até o período entre as medições são diferentes...então eles não tem como nem pesquisar no colega do lado para ver se o colega está fazendo igual (Entrevista, 30/03/2004)

Na sequência dos miniciclos a professora é pressionada a orientar os casos particulares dos alunos e toma consciência dos seus "jeitos próprios" de resolverem os problemas, diferentes da "forma como (eu) resolvo no quadro" (Entrevista, data). Assim, passa a legitimar os outros procedimentos usados por eles para fazer o arredondamento das médias, definir o número de pessoas e escolher a sequência de cálculos para resolver os problemas. Durante a entrevista, a professora reflete sobre as dificuldades por ela enfrentadas em sala de aula e sobre as percepções dos alunos sobre a atividade da conta de água, manifestadas também em entrevistas:

39.Vanessa: todos os alunos que eu entrevistei disseram que é diferente ((regra de três $))$...

40.Telma: aplica-se a regra de três no cotidiano ... mas não pode ser regra de três porque ...regra de três é uma coisa que eles fazem dentro da escola ...eu acho que pode estar havendo esta distância...escola é escola...minha casa é minha casa... a rua é a rua...então o que eu faço lá no supermercado...não é o que o eu faço na escola...é uma regra de três lá no supermercado...mas não é a da escola...porque escola é escola... (Entrevista, 30/03/2004) 
Nesse momento, ela mostra ter tomado consciência dos diferentes significados atribuídos pelos alunos à regra de três, quando aplicada em situações do cotidiano e explica como compreende essa diferenciação.

\section{Considerações finais}

Concluímos que a perspectiva de análise adotada neste artigo nos permitiu avançar na compreensão de outras aprendizagens, tanto da professora quanto dos alunos, que não tinham sido alvo de análise anteriores. Em particular, a análise dos miniciclos potencialmente expansivos de ações de aprendizagem nos revelou um conjunto de aprendizagens não previstas no planejamento inicial da professora que foram potencializadas pela resolução de problemas que envolvem situações do cotidiano dos alunos e pela forma como a atividade se desenvolveu.

Essa perspectiva de análise permitiu revelar um conjunto de aprendizagens expansivas que vão muito além de uma simples aquisição de um procedimento mecânico de cálculo. Isso ocorreu porque foi criado em sala de aula um contexto de crítica que levou a uma expansão do significado de alguns procedimentos usados na resolução de problemas que envolvem situações do cotidiano: arredondamento de números decimais e comparação de números por estimativas; transformação de unidades de volume e capacidade; localização de dados em um formulário para fazer um cálculo; definição de dados para resolver um problema considerando a situação específica de cada um; escolha da sequência de cálculos a ser utilizada para resolver um determinado problema. Levou ainda a uma ampliação do significado dos números, que deixam de traduzir uma simples contagem de pessoas e incorporam as ações em que essas pessoas estão envolvidas. Os alunos tomam também consciência de que o arredondamento de números que expressam situações do seu cotidiano pode ter desdobramentos em sua vida, como o pagamento acima por um serviço prestado.

Finalizando, cabe destacar o papel da pesquisadora na tomada de consciência das aprendizagens pelos próprios alunos e pela professora, potencializada pelas reflexões suscitadas no momento das entrevistas. Elas se revelaram também como momentos em que surgem oportunidades de expansão de significados, quando algumas tensões foram explicitadas na interação com a pesquisadora. Assim, nosso entendimento é que este estudo contribui para mostrar como a pesquisa em Educação Matemática pode ir além da descrição e análise das práticas em sala de aula, influenciando na própria aprendizagem dos sujeitos pesquisados, além, evidentemente, da aprendizagem das pesquisadoras. 


\section{Referências}

BATESON, G. Steps to an ecology of mind. Chicago and London: The University of Chicago Press, 1972.

BRASIL. Secretaria de Educação Fundamental. Parâmetros curriculares nacionais: Matemática. Brasília, 1998.

DAVID, M. M.; WATSON, A. Participating in what? Using situated cognition theory to illuminate differences in classroom practices. In: WATSON, A.; WINBOURNE, P. (Ed..) New directions for situated cognition in mathematics education. New York: Springer, 2008, p. 31-57.

DAVID, M. M.; TOMAZ, V.S. Researching classrooms: Historicity as a perspective to analyze a geometry class. In: TZEKAKI, M; KALDRIMIDOU, M. SAKONIDIS, H (Ed.), Proceedings of the 33rd Conference of the International Group for the Psychology of Mathematics Education, Thessaloniki, 2009. v. 2, p. 377-384.

DAVID, M. M.; TOMAZ, V. S. The role of visual representations for structuring classroom mathematical activity. Educational Studies in Mathematics, Dordrecht, v. 80, p. 413-431, Jul. 2012.

DAVID, M. M.; TOMAZ, V. S. Uma perspectiva histórico-cultural sobre a mudança de regras na atividade matemática escolar na sala de aula. Jornal Internacional de Estudos em Educação Matemática, São Paulo, v. 7, n.2, p. 217-238, Dez. 2014.

ENGESTRÖM, Y. Learning by expanding: an activity-theoretical approach to developmental research. Helsinki: Orienta-Konsultit, 1987.

ENGESTRÖM, Y. Non Scolae Vitae Discimus: toward overcoming the encapsulation of school learning. Learning and Instruction, Finland, v.1, n.3, p. 243-259, 1991.

ENGESTROM, Y. Developmental studies of work as a testbench of activity theory: The case of primary care medical practice. In CHAIKLIN, S.; LAVE, J. (Ed.). Understanding practice: perspectives on activity and context. Cambridge: Cambridge University Press, 1996. p. 64-103.

ENGESTRÖM, Y. Expansive Learning at Work: toward an activity theoretical reconceptualization. Journal of Education and Work, v. 14, n. 1, p. 133-156, 2001.

ENGESTRÖM, Y; SANNINO, A. Studies of expansive learning: Foundations, findings and future challenges. Educational Research Review, v. 5, p. 1-24, 2010.

GREEN, J. L.; DIXON, C. N.; ZAHARLICK, A. Ethnography as a logic of inquiry. In FLOOD, J.; LAPP, D.; SQUIRE, J. R.; JENSEN, J. M. (Ed.). Handbook of research on teaching the English language arts. 2. ed. Mahwah: Lawrence Erlbaum, 2003. p. 201-224.

LAVE, J.; WENGER, E. Situated learning: legitimate peripheral participation. New York: Cambridge University Press, 1991.

LAVE, J. Situating Learning in Communities of Practice. In: RESNICK, L.; LEVINE, J.; TEASLEY, S. (Ed.). Perspectives on socially shared cognition. 2. ed. Washington: American Psychological Association, 1993. p. 63-82.

LEONT'EV, A. N. Activity, consciousness, personality. Englewood Cliffs: Prentice-Hall, 1979. 
RUSSELL, D. R. Uses of activity theory in written communication research. In SANNINO, A; DANIELS, H.; GUTIÉRREZ, K.D. (Ed.). Learning and expanding with activity theory. New York: Cambridge University Press, 2009. p. 40-52.

TOMAZ, V. S. Prática de transferência de aprendizagem situada em uma atividade interdisciplinar. 2007. 303 f. Tese (Doutorado em Educação) - Faculdade de Educação, Universidade Federal de Minas Gerais, Belo Horizonte, 2007.

TOMAZ, V. S.; DAVID, M. M. Classroom activity promoting students' learning about the use of drawings in geometry. In: UBUZ, B (Ed.), Proceedings of the $\mathbf{3 5}^{\text {th }}$ Conference of the International Group for the Psychology of Mathematics Education. Ankara, 2011. v. 4, p. 257-264.

TOMAZ,V. S.; DAVID, M. M. Interdisciplinaridade e aprendizagem da Matemática em sala de aula. Belo Horizonte: Autêntica, 2008.

TOMAZ, V. S.; DAVID, M. M. How students' everyday situations modify classroom mathematical activity: the case of water consumption. Journal for Research in Mathematics Education, Reston, VA, v. 46, n. 4, p. 455-496, Jul. 2015.

Submetido em Abril de 2015. Aprovado em Julho de 2015. 